\title{
Geographic distribution of the invasive cattle tick Rhipicephalus microplus, a country-wide survey in Benin
}

\author{
E.M. De Clercq ${ }^{1}$, S.O. Vanwambeke ${ }^{1}$, M. Sungirai ${ }^{2}$, S. Adehan ${ }^{3}$, R. Lokossou ${ }^{4}$, \\ M. Madder ${ }^{2,5}$ \\ (1) Georges Lemaître Institute for Earth and Climate research, Université \\ catholique de Louvain, Place Louis Pasteur 3, 1348 Louvain-la-Neuve, Belgium \\ (2) Vector Biology Unit, Institute of Tropical Medicine, Nationalestraat 155, 2000 \\ Antwerp, Belgium
}

(3) Ministère de l'Agriculture de l'Elevage et de la Pêche/CeRPA-OP/Service Recherche Développement, 03 BP 2900 Cotonou Route de l'Aéroport, Benin

(4) La Direction de l'élevage du Ministère de l'Agriculture, de l'élevage et de la pèche, BP 2041 PK 05 Cotonou Route de Porto-Novo, Benin

(5) Department of Veterinary Tropical Diseases, Faculty of Veterinary Science, University of Pretoria, Onderstepoort 0110, South Africa

(*) Corresponding author, eva.declercq@uclouvain.be, phone + 3210479040 , fax + 3210472877

\begin{abstract}
The cattle tick Rhipicephalus microplus is currently invading the West African region, and little information is available on the spread of this exotic tick in this region. We set out a country-wide field survey to determine its current distribution in Benin. Ticks were collected on cattle from 106 farms selected by random sampling covering all regions of the country. $R$. annulatus was found in $70 \%$ of all farms, $R$. decoloratus was found in $42 \%, R$. geigyi was found on $58 \%$, and $R$. microplus was found on $49 \%$ of all farms. There is a clear geographic separation between the indigenous $R$. species and $R$. microplus. $R$. annulatus occurs mainly in the northern departments, but it was also observed in smaller amounts in locations in the south. The presence of $R$. decoloratus is limited to the northern region, and in most locations, this tick makes up a small proportion of the collected ticks. The tick R. geigyi tends to be dominant, but occurs only in the four northern departments. The observations concerning $R$. microplus are entirely different, this species occurs in the southern and central region. The results of this survey confirm the invasive character and displacement properties of $R$. microplus, since in less than a decade it has colonized more than half of the country and has displaced indigenous ticks of the same genus in a large number of the sampled locations.
\end{abstract}

\section{Keywords}

Rhipicephalus microplus; Babesia bovis; geographic tick distribution; countrywide tick survey; cattle 


\section{Introduction}

Global costs of tick-borne diseases in cattle can be estimated between 13.9 and 18.7 billion US\$ per year (DeCastro, 1997). The major pest of cattle worldwide is the cattle tick Rhipicephalus microplus, transmitting Babesia bigemina, B. bovis and Anaplasma marginale. The related economic losses were deemed so high that in the USA this tick has been eradicated at huge expenses by long-term acaricide use and strict control of animal movement (Corson et al., 2004). Despite their efforts, other countries have not been able to eradicate $R$. microplus (De Castro, 1997Pegram et al., 2000). The cattle tick is well established in Latin America (Evans et al., 2000) and Australasia (Estrada-Peña and Venzal, 2006) and is currently invading the West African region where it was first reported in 2007(Madder et al., 2007), . It has managed to establish itself and has replaced the indigenous Rhipicephalus (Boophilus) species (Madder et al., 2011). This situation has also been observed in other West-African countries. R. microplus was found in massive numbers during a cross-sectional survey in the department of Mono, in the south of Benin (Madder et al., 2012a).

The spread of $R$. microplus threatens rural populations, which often depend on livestock for their survival. Little to no information is available on the climatic limits of this tick in the West-African region. To fill this gap, we set out a country-wide field survey in order to determine the current distribution of R. microplus in Benin.

\section{Material and Methods}

\section{Study area}

Benin, officially the Republic of Benin, borders Togo to the west, Nigeria to the east and Burkina Faso and Niger to the north. Its geographic extent is situated between latitudes $6^{\circ}$ and $13^{\circ} \mathrm{N}$, and longitudes $0^{\circ}$ and $4^{\circ} \mathrm{E}$. Administratively, Benin is divided into 12 departments (Fig. 1). Benin's climate is hot and humid. Although the total yearly precipitation is similar throughout the country, varying between 1000 and $1300 \mathrm{~mm}$, three different rainfall patterns can be observed (Fig. 2). The north of the country has one short rainy season, with a high precipitation peak in August. This peak rapidly declines after September. The central region 


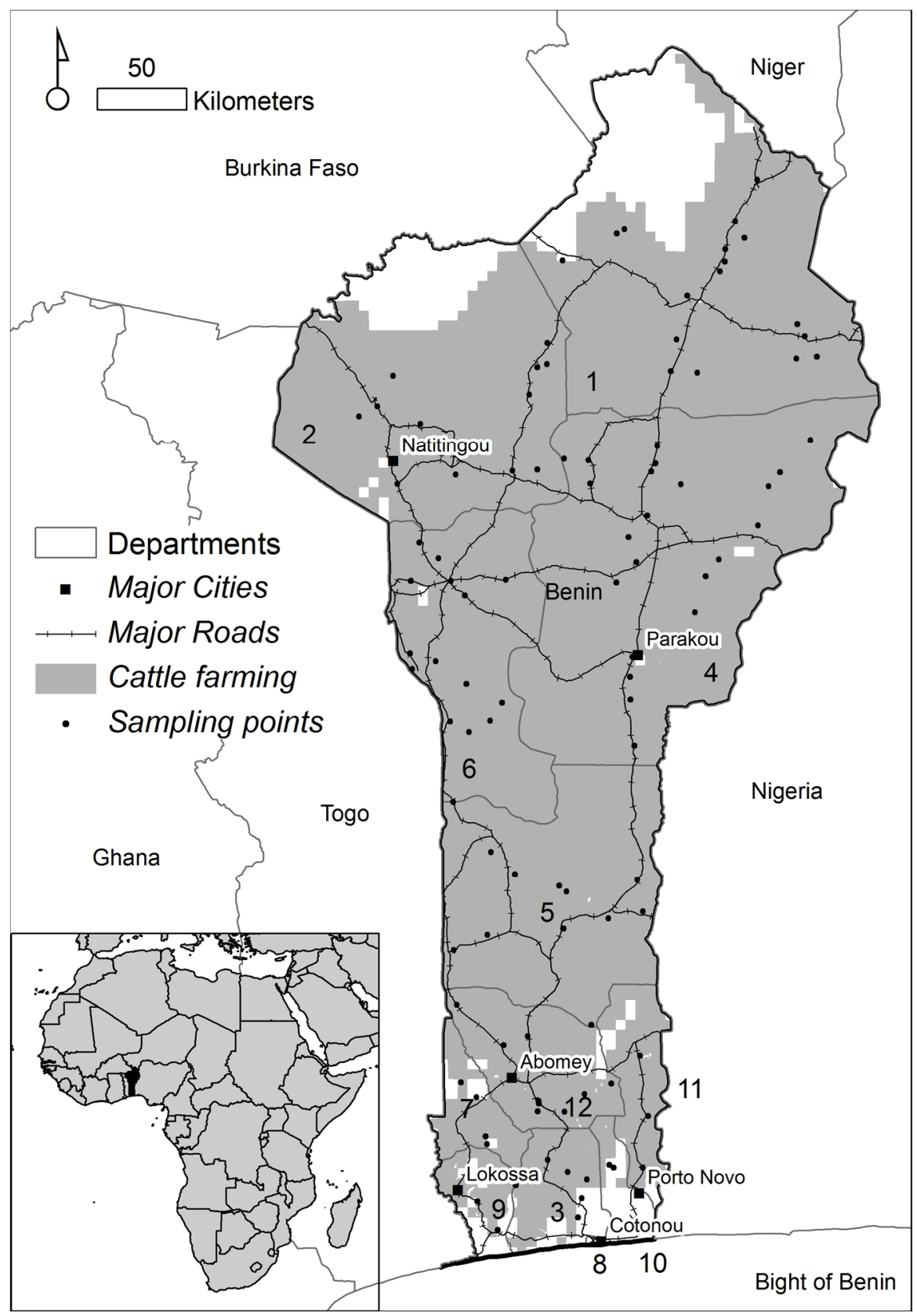

Fig. 1. Locations of the farms that were sampled for the country-wide survey of Benin. The numbers on the map refer to the ID number of the departments; their names are listed in Table 1.

features a long rainy season from the beginning of March to the end of October. Monthly rainfall values are not higher than $160 \mathrm{~mm}$. There is a slight dip in rainfall in August, but both peaks are of the same height. The southern region has two rainy and two dry seasons per year. The principal rainy season is from April to late July, with a shorter, less intense rainy period from late September to November. The main dry season is from December to April, with a short cooler dry season from late July to early September (Hijmans et al., 2005). 
In total, 106 farms were selected by random sampling (Fig. 1). The entire country was considered suitable for cattle raising, with the exception of a small region in the north and in the south of the country (Wint and Robinson, 2007).

In warm regions, tick survival is to a large degree dependent on the available humidity, and tick abundance starts to decline at the end of the rainy season. As the rainfall pattern features a north-south gradient (Fig. 2), the field missions were organized accordingly (Table 1). Sampling took place from 12-19 September 2011 in the northern region, from 7-16 November 2011 in the central region, and between 4 and 13 December 2011 in the south. Data from three additional points in the department of Atakora in the northwest were collected on October $5^{\text {th }} 2011$. The number of sampling points per department was proportional to the area of each department. In the northern part of the country, the departments are more extensive, therefore more sample points were taken in Alibori, Atakora, Borgou, Donga and Collines. In smaller departments in the southern part of the country (e.g. Ouémé, Plateau and Kouffo), a lower number of farms were sampled. In the Littoral no ticks were collected, since this department coincides with the country's capital Cotonou and contains no land suitable for cattle.

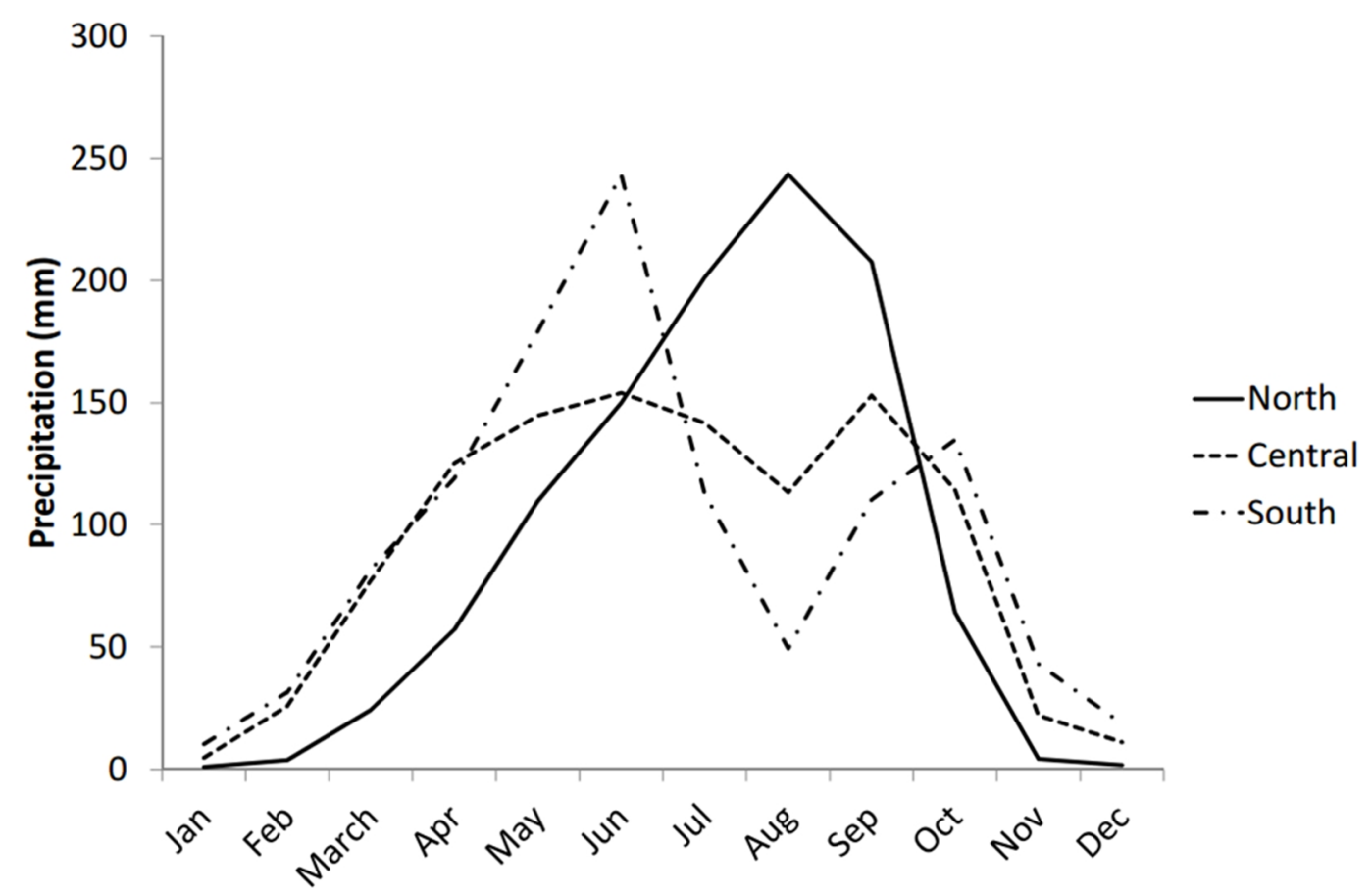

Fig. 2. Rainfall pattern in the three regions in Benin (Hijmans et al., 2005) 
Table 1. Sample points in the different departments. The ID numbers in column 1 refer to the numbers on the map in Fig. 1.

\begin{tabular}{ccccc}
\hline ID & Department & Region & Field mission & Nr. of farms \\
\hline 1 & Alibori & North & September & 18 \\
2 & Atakora & North & September \& October & 13 \\
3 & Atlantique & South & December & 5 \\
4 & Borgou & North & November & 22 \\
5 & Collines & Centre & December & 11 \\
6 & Donga & North & November & 15 \\
7 & Kouffo & Centre & December & 4 \\
8 & Littoral & South & - & 0 \\
9 & Mono & South & December & 3 \\
10 & Ouémé & South & December & 2 \\
11 & Plateau & Centre & December & 3 \\
12 & Zou & Centre & December & 10 \\
\hline
\end{tabular}

\section{Tick collection}

On each of the 106 farms visited, ticks were collected from at least two domestic bovine hosts (ICTTD, 2007; Pérez De Leán et al., 2010). The full body was sampled using forceps, with the exception of the flank lying on the ground. Where possible, all ticks on the inspected body were removed. On highly tick-infested animals, a sub-sample of the ticks present was collected, but care was taken to collect ticks from the different predilection sites: the base of tail and perianal region, perineum, legs, axillae, hooves, udder, scrotum, belly, dewlap, head and ears (Peter et al., 1998; ICTTD, 2007). The ticks were stored in plastic vials containing $70 \%$ alcohol, which were labelled using the sampling date and the village name. Smartphones were used for the recording of geographic coordinates of each farm. For data management, two software applications were used simultaneously: (i) EpiCollect, a generic freeware developed at the Imperial College of Londen (Aanensen et al., 2009; Madder et al., 2012b), and (ii) VECMAP, currently under development by an ESA-funded European Consortium (ESA, 2012). Both applications allow the collection of geo-localized field data, including geographic coordinates and forms for an in-situ questionnaire. Both applications use a wireless internet connection to transfer the data to a centralized database on the worldwide web. 


\section{Tick identification}

Tick identification was done based on morphology using a Zeiss stereoscope (80fold magnification) and a Zeiss microscope (100 to 200-fold magnification). Only adult specimens were identified up to species level using both taxonomic descriptions (Walker et al., 2003) and morphological keys (Madder, 2012a, 2012b). The identification of a subset of 10 individuals of each of the four Rhipicephalus (Boophilus) tick species was confirmed molecularly using a PCRRFLP test (Lempereur et al., 2010). Although species of other genera were collected during the different surveys (mainly Amblyomma, Hyalomma and Rhipicephalus), they are not discussed in this article, partly because they made up a minority of the collected ticks and partly because no changes have been observed in their distribution since the last country-wide survey (Vercruysse et al., 1982).

For each sample point, the total number of identifiable $R$. (Boophilus) spp. specimens was counted, and the proportion for each of the four encountered species was calculated.

\section{Results}

In total, close to 14.000 ticks were collected and identified, of which 12.378 belonged to the species R. Boophillus. R. annulatus was found in $70 \%$ of the farms, $R$. decoloratus was found on $42 \%$ of all farms, $R$. geigyi was found on $58 \%$ of all farms, and $R$. microplus was found on $49 \%$ of all farms. The morphological identification of the four Rhipicephalus (Boophilus) tick species was confirmed by a PCR-RFLP test. A number of ticks however, were found with hybrid morphology, featuring most characteristics of $R$. microplus. except that the $1^{\text {st }}$ segment of the palps showed a ventro-internal protuberance bearing a pectinate seta. These individuals will be analysed further using molecular tools.

We supply maps of the geographic distribution of the four Rhipicephalus (Boophilus) species in Fig. 3. There is a clear geographic separation between the indigenous R. (Boophilus) species and R. microplus. R. annulatus occurs mainly in the northern departments (Alibori, Atacora, Borgou and Donga) where it reaches high proportions, but it was also observed in some locations in the south 

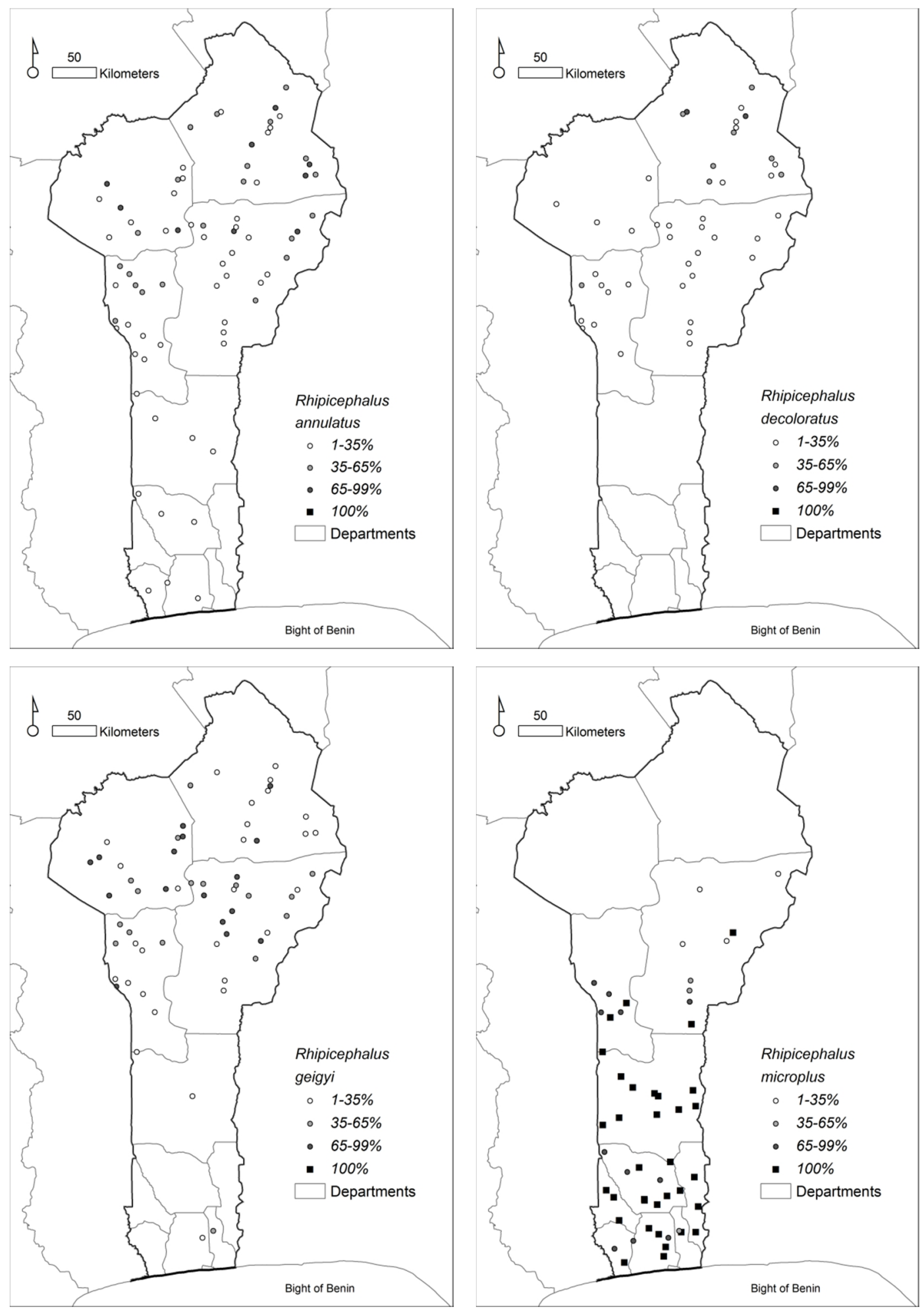

Fig. 3. Observed distribution of four Rhipicephalus (Boophilus) species in Benin

(Collines, Zou, Mono and Atlantique), here it constitutes a minority of the collected $R$. (Boophilus) spp. ticks. The presence of $R$. decoloratus is limited to the northern region, and in most locations, this tick makes up a feeble proportion of the collected ticks. The highest proportions are situated in the northeast of the 
country (Alibori). In contrast, the species R. geigyi tends to be dominant, but occurs only in the four northern departments. This species was equally found in one location in the central region (Collines), and two locations in the south (Atlantique and Ouémé), where it constitutes a feeble fraction of the total number of collected ticks. The observations concerning $R$. microplus are entirely different, this species occurs mainly in the southern and central region, and in the most southern of the northern departments (Borgou and Donga). In sites where it is found, this tick makes up the larger part of the sample and also occurs in high numbers. On average, $63 R$. microplus specimens were collected per animal sampled. For the indigenous $R$. spp species, the number of tick individuals per sampled animal was respectively 7 for $R$. annulatus, 9 for $R$. geigyi and 5 for $R$. annulatus. In the south, nearly all collected ticks were identified as $R$. microplus. It is also noteworthy that $R$. microplus is the only species that made up $100 \%$ of a R. (Boophilus) spp. sample. The three other $R$. (Boophilus) spp. ticks co-exist in their environment.

These results can also be consulted at the project website:

http://epicollectserver.appspot.com/project.html?name=TickRisk_3.

\section{Discussion \& Conclusion}

This survey of more than 100 locations provides a first and comprehensive country-wide survey of the distribution of the invasive species $R$. microplus in Benin. Although the presence of this vector of cattle fever was confirmed in West Africa, there was no information on the extent of its current distribution in the country (Madder et al., 2012a).

This survey is an invaluable dataset both for local and regional decision makers to estimate the economic burden and to design an efficient control strategy for this cattle pest, as well as for scholars studying the spread of this invasive species.

The most recent publications about the presence of $R$. (Boophilus) ticks in Benin only report $R$. annulatus, $R$. geigyi and $R$. decoloratus. The first two being present in the entire country and $R$. decoloratus present in the extreme north (Vercruysse et al., 1982). According to the authors $R$. decoloratus replaces $R$. geigyi, the most common species, in the more arid regions of the country although a small number of this species was also observed on ovines in the south of the country (Farougou 
et al., 2007a). Later studies performed by Farougou and colleagues in the northern departments (Farougou et al., 2006, 2007b) do not mention the presence of $R$. decoloratus any more although this species was collected in the present study in the northern departments, although in low numbers.

This survey also reveals the presence of hybrid $R$. spp. specimens with morphological characteristics of more than one species. It was assumed that these are sterile hybrids resulting from the mating of an indigenous $R$. spp. female with an invasive $R$. microplus male. These individuals will be the subject of further research in the coming months.

As $R$. microplus is considered to be a coastal tick, and requires a relatively high level of humidity, it was alarming to observe the presence of $R$. microplus in the northern departments of Borgou and Donga. The results of this survey confirm the invasive character and displacement properties of $R$. microplus, since in less than a decade it has colonized more than half of the country and has displaced indigenous ticks of the same genus in a large number of the sampled locations. So far R. microplus only remains absent from the two most northern departments, known to harbour a large quantity of cattle. Moreover, it is quite possible that this tick has not yet reached its full climatic range and it might spread further northwards into more arid regions during the following years. Since cattle are extremely mobile in Benin, and both small and large (international) transhumance is a widespread practice, the spread of $R$. microplus could be quite rapid and is already causing regional concern. As a result of the frequent and seasonal cattle migration, mainly north-south, more research is necessary to determine the difference between established and temporal $R$. microplus populations, the latter being re-introduced by migrating animals on a yearly basis. Furthermore, the displacement of $R$. annulatus, $R$. decoloratus and $R$. geigyi in the central and southern departments could have altered the epidemiology of Babesia bovis and B. bigemina. The main concern however is the observed acaricide resistance of $R$. microplus, leading to inappropriate use of acaricides and other chemicals (Madder et al., 2011).

Although the sampling was performed according to a standardized and repeatable method, the resulting data are poorly suited for the study of tick abundance. This is because the abundance of ticks is highly dependent on human factors, such as general health condition of the herd and the (good) use of acaricides by the 
herdsmen. Also, it was not possible to sample all 106 farms during the same period in time. A part of the farms, situated in the northern departments, was visited during the rainy season to increase the likelihood of finding a sufficient number of ticks, while the farms situated in the central and southern region were visited at the end of the rainy season. Especially the southern departments are suitable for ticks throughout the year because of the tropical rainforest climate. Given the fact that ticks were found in sufficient number at all locations, the data provide a good baseline for presence/absence-studies.

\section{Acknowledgements}

We would like to thank the staff of the Direction de l'Elevage (DE) and the Ministry of Agriculture (MAEP) in Benin for their help during the field work. We are very grateful to all people that assisted us during the tick collection, especially the cattle owners and herdsmen. This work was funded by the Belgian Science Policy Programs (Belspo, SR/00/144).

\section{References}

Aanensen, D.M., Huntley, D.M., Feil, E.J., Al-Own, F., and Spratt, B.G. (2009). EpiCollect: Linking smartphones to web applications for epidemiology, ecology and community data collection. PLoS ONE 4, e6968.

Corson, M.S., Teel, P.D., and Grant, W.E. (2004). Microclimate influence in a physiological model of cattle-fever tick (Boophilus spp.) population dynamics. Ecological Modelling 180, 487-514.

DeCastro, J.J. (1997). Sustainable tick and tickborne disease control in livestock improvement in developing countries. Veterinary Parasitology 71, 77-97.

ESA (2012). VECMAP - Mosquito habitat mapping service: http://iap.esa.int/projects/health/vecmap.

Estrada-Peña, A., and Venzal, J.M. (2006). High-resolution predictive mapping for Boophilus annulatus and B. microplus (Acari: Ixodidae) in Mexico and Southern Texas. Veterinary Parasitology 142, 350-358.

Evans, D.E., Martins, J.R., and Guglielmone, A.A. (2000). A review of the ticks (Acari, Ixodida) of Brazil, their hosts and geographic distribution - 1. The state of Rio Grande do Sul, Southern Brazil. Mem Inst Oswalso Cruz, Rio De Janeiro 95, 453-470.

Farougou, S., Kpodekon, M., Adakal, H., Sagbo, R., and Boko, C. (2007a). Seasonal abundance of ticks (Acari: Ixodidae) infesting sheep in the southern area of Benin. Revue De Medecine Veterinaire 158, 627-632.

Farougou, S., Kpodekon, M., Tchabode, D.M., Youssao, A.K.I., and Boko, C. (2006). Seasonal abundance of cattle tick (Acari: Ixodidae) parasites in the Sudanese part of Benin: Case of the Atacora and Donga Departments. Annales De Medecine Veterinaire 150, 145-152.

Farougou, S., Tassou, A.W., Tchabode, D.M., KPodekon, M., Boko, C., and 
Youssao, A.K.I. (2007b). Tiques et hémoparasites du bétail dans le nordBénin. Revue Med. Vet. 158, 463-467.

Hijmans, R.J., Cameron, S.E., Parra, J.L., Jones, P.G., and Jarvis, A. (2005). WORLDCLIM: Very high resolution interpolated climate surfaces for global land areas. International Journal of Climatology 25, 1965-1978.

ICTTD (2007). Surveys to establish the local, provincial or national distribution of ticks. Newsletter on ticks and tick-borne diseases of livestock in the tropics, nr. 32.

Lempereur, L., Geysen, D., and Madder, M. (2010). Development and validation of a PCR-RFLP test to identify African Rhipicephalus (Boophilus) ticks. Acta Tropica 114, 55-58.

Madder, M. (2012a). I-Spot Key for the identification of $R$. Boophilus females: http://www.ispot.org.uk/webkeys/keyintroduction.jsp?selectedKey=webkey s/Rhip icephalus\%28Boophilus\%29 females.0.1.

Madder, M. (2012b). I-Spot Keys for the identification of $R$. Boophilus males: http://www.ispot.org.uk/webkeys/keyintroduction.jsp?selectedKey=webkey s/Rhip icephalus\%28Boophilus\%29_males.0.2.

Madder, M., Adehan, S., De Deken, R., Adehan, R., and Lokossou, R. (2012a). New foci of Rhipicephalus microplus in West Africa. Experimental and Applied Acarology 56, 385-390.

Madder, M., Thys, E., Achi, L., Touré, A., and De Deken, R. (2011). Rhipicephalus (Boophilus) microplus: a most successful invasive tick species in West-Africa. Experimental and Applied Acarology 53, 139-145.

Madder, M., Thys, E., Geysen, D., Baudoux, C., and Horak, I. (2007). Boophilus microplus ticks found in West Africa. Exp Appl Acarol 43, 233-234.

Madder, M., Walker, J.G., Van Rooyen, J., Knobel, D., De Clercq, E.M., Vanwambeke, S.O., and Berkvens, D. (2012b). e-Surveillance in Animal Health: use and evaluation of mobile tools. Parasitology (Accepted).

Pegram, R.G., David Wilson, D., and Hansen, J.W. (2000). Past and present national tick control programs: Why they succeed or fail. In Annals of the New York Academy of Sciences, pp. 546-554.

Pérez De Leán, A.A., Strickman, D.A., Knowles, D.P., Fish, D., Thacker, E., De La Fuente, J., Krause, P.J., Wikel, S.K., Miller, R.S., Wagner, G.G., et al. (2010). One health approach to identify research needs in bovine and human babesioses: Workshop report. Parasites and Vectors 3, 36.

Peter, T.F., Perry, B.D., O’Callaghan, C.J., Medley, G.F., Shumba, W., Madzima, W., Burridge, M.J., and Mahan, S.M. (1998). Distributions of the vectors of heartwater, Amblyomma hebraeum and Amblyomma variegatum (Acari: Ixodidae), in Zimbabwe. Experimental and Applied Acarology 22, 725-740.

Vercruysse, J., Lafia, S., and Camicas, J.L. (1982). Les tiques (Amblyommidae) parasites des bovins en République populaire du Benin. Rev. Elev. Med. Vet. Pays Trop. 35, 361-364.

Walker, A.., Bouattour, A., Camicas, J.L., Estrada-Peña, A., Horak, I.G., Latif, A.A., Pegram, R.G., and Preston, P.M. (2003). Ticks of domestic animals in Africa: A guide to identification of species. (Edinburgh, Scotland: The university of Edinburgh).

Wint, W., and Robinson, T.P. (2007). Gridded livestock of the world (FAO, Rome). 


\section{Annex 1 - Collected data}

Table 2. Geographic coordinates of the visited farms, collection data and collected ticks. Four Rhipicephalus species were encountered during identification. A value ' 0 ' indicates absence, ' 1 ' indicates presence of a given species in the sample.

\begin{tabular}{|c|c|c|c|c|c|c|}
\hline \multirow[b]{2}{*}{ Latitude } & \multirow[b]{2}{*}{ Longitude } & \multirow[b]{2}{*}{ Date } & \multicolumn{4}{|c|}{ Rhipicephalus } \\
\hline & & & annulatus & decoloratus & geigyi & microplus \\
\hline 10.763 & 2.926 & $12 / 09 / 2011$ & 1 & 1 & 1 & 0 \\
\hline 10.933 & 2.829 & $13 / 09 / 2011$ & 1 & 1 & 1 & 0 \\
\hline 11.277 & 3.040 & $13 / 09 / 2011$ & 1 & 1 & 1 & 0 \\
\hline 11.390 & 3.068 & $13 / 09 / 2011$ & 1 & 1 & 1 & 0 \\
\hline 10.772 & 2.791 & $13 / 09 / 2011$ & 1 & 1 & 1 & 0 \\
\hline 10.835 & 3.428 & $14 / 09 / 2011$ & 1 & 1 & 1 & 0 \\
\hline 10.845 & 3.531 & $14 / 09 / 2011$ & 1 & 1 & 1 & 0 \\
\hline 10.949 & 3.469 & 14/09/2011 & 1 & 1 & 0 & 0 \\
\hline 11.010 & 3.431 & $14 / 09 / 2011$ & 1 & 1 & 1 & 0 \\
\hline 11.154 & 2.875 & $15 / 09 / 2011$ & 1 & 0 & 1 & 0 \\
\hline 11.447 & 3.164 & $15 / 09 / 2011$ & 1 & 1 & 0 & 0 \\
\hline 11.327 & 3.065 & $15 / 09 / 2011$ & 1 & 1 & 1 & 0 \\
\hline 11.741 & 3.228 & $15 / 09 / 2011$ & 1 & 1 & 0 & 0 \\
\hline 11.532 & 3.118 & $15 / 09 / 2011$ & 1 & 1 & 1 & 0 \\
\hline 11.332 & 2.244 & $16 / 09 / 2011$ & 1 & 0 & 1 & 0 \\
\hline 11.491 & 2.558 & $16 / 09 / 2011$ & 1 & 1 & 0 & 0 \\
\hline 11.469 & 2.518 & $16 / 09 / 2011$ & 1 & 1 & 1 & 0 \\
\hline 11.333 & 2.245 & $16 / 09 / 2011$ & 1 & 0 & 1 & 0 \\
\hline 10.807 & 2.166 & $17 / 09 / 2011$ & 1 & 1 & 1 & 0 \\
\hline 10.652 & 2.075 & $17 / 09 / 2011$ & 1 & 0 & 1 & 0 \\
\hline 10.792 & 2.117 & $17 / 09 / 2011$ & 1 & 0 & 1 & 0 \\
\hline 10.915 & 2.167 & $17 / 09 / 2011$ & 1 & 0 & 1 & 0 \\
\hline 10.265 & 1.991 & 17/09/2011 & 1 & 1 & 1 & 0 \\
\hline 10.352 & 1.631 & $18 / 09 / 2011$ & 1 & 1 & 1 & 0 \\
\hline 10.244 & 1.703 & $18 / 09 / 2011$ & 1 & 0 & 1 & 0 \\
\hline 10.271 & 2.116 & $18 / 09 / 2011$ & 1 & 0 & 1 & 0 \\
\hline 10.504 & 1.526 & $18 / 09 / 2011$ & 1 & 0 & 1 & 0 \\
\hline 10.198 & 1.409 & 19/09/2011 & 1 & 0 & 1 & 0 \\
\hline 10.593 & 1.307 & $5 / 10 / 2011$ & 1 & 0 & 1 & 0 \\
\hline 10.541 & 1.213 & $5 / 10 / 2011$ & 0 & 1 & 1 & 0 \\
\hline 10.748 & 1.386 & $5 / 10 / 2011$ & 1 & 0 & 1 & 0 \\
\hline 6.731 & 2.651 & $11 / 10 / 2011$ & 0 & 0 & 0 & 1 \\
\hline 9.321 & 2.597 & $7 / 11 / 2011$ & 1 & 1 & 1 & 1 \\
\hline 9.219 & 2.584 & $7 / 11 / 2011$ & 1 & 1 & 1 & 1 \\
\hline 8.871 & 2.607 & $7 / 11 / 2011$ & 0 & 0 & 0 & 1 \\
\hline 9.104 & 2.588 & $7 / 11 / 2011$ & 1 & 1 & 0 & 1 \\
\hline 9.802 & 2.617 & $8 / 11 / 2011$ & 1 & 1 & 1 & 0 \\
\hline 9.927 & 2.576 & $8 / 11 / 2011$ & 1 & 1 & 1 & 0 \\
\hline 9.548 & 2.914 & $8 / 11 / 2011$ & 1 & 0 & 1 & 0 \\
\hline
\end{tabular}




\begin{tabular}{|c|c|c|c|c|c|c|}
\hline \multirow[b]{2}{*}{ Latitude } & \multirow[b]{2}{*}{ Longitude } & \multirow[b]{2}{*}{ Date } & \multicolumn{4}{|c|}{ Rhipicephalus } \\
\hline & & & annulatus & decoloratus & geigyi & microplus \\
\hline 9.699 & 2.515 & $8 / 11 / 2011$ & 1 & 1 & 1 & 1 \\
\hline 10.258 & 3.344 & $9 / 11 / 2011$ & 1 & 0 & 1 & 0 \\
\hline 9.730 & 2.968 & $9 / 11 / 2011$ & 1 & 0 & 1 & 1 \\
\hline 10.185 & 3.287 & $9 / 11 / 2011$ & 1 & 1 & 1 & 0 \\
\hline 9.815 & 3.036 & $9 / 11 / 2011$ & 1 & 0 & 1 & 1 \\
\hline 9.987 & 3.234 & $9 / 11 / 2011$ & 1 & 1 & 1 & 0 \\
\hline 10.261 & 2.693 & $10 / 11 / 2011$ & 1 & 0 & 1 & 1 \\
\hline 10.421 & 3.500 & $10 / 11 / 2011$ & 1 & 1 & 1 & 1 \\
\hline 10.195 & 2.842 & $10 / 11 / 2011$ & 1 & 1 & 1 & 0 \\
\hline 10.200 & 2.383 & $11 / 11 / 2011$ & 1 & 1 & 1 & 0 \\
\hline 10.391 & 2.725 & $11 / 11 / 2011$ & 1 & 1 & 1 & 0 \\
\hline 10.037 & 2.673 & $11 / 11 / 2011$ & 1 & 1 & 1 & 0 \\
\hline 10.302 & 2.714 & $11 / 11 / 2011$ & 1 & 1 & 1 & 0 \\
\hline 10.327 & 2.253 & $12 / 11 / 2011$ & 1 & 1 & 1 & 0 \\
\hline 10.319 & 2.376 & $12 / 11 / 2011$ & 1 & 1 & 1 & 0 \\
\hline 9.820 & 1.617 & $13 / 11 / 2011$ & 1 & 1 & 1 & 0 \\
\hline 9.705 & 1.679 & $13 / 11 / 2011$ & 1 & 1 & 1 & 0 \\
\hline 9.900 & 1.518 & $13 / 11 / 2011$ & 1 & 0 & 1 & 0 \\
\hline 9.633 & 1.749 & $14 / 11 / 2011$ & 1 & 1 & 1 & 0 \\
\hline 9.705 & 1.476 & $14 / 11 / 2011$ & 1 & 1 & 1 & 0 \\
\hline 9.712 & 1.957 & $14 / 11 / 2011$ & 1 & 1 & 1 & 0 \\
\hline 9.260 & 1.484 & $15 / 11 / 2011$ & 1 & 1 & 1 & 0 \\
\hline 9.184 & 1.757 & $15 / 11 / 2011$ & 1 & 0 & 1 & 1 \\
\hline 9.339 & 1.471 & $15 / 11 / 2011$ & 1 & 1 & 1 & 0 \\
\hline 9.298 & 1.602 & $15 / 11 / 2011$ & 1 & 1 & 1 & 1 \\
\hline 9.090 & 1.937 & $16 / 11 / 2011$ & 1 & 0 & 0 & 1 \\
\hline 8.941 & 1.771 & $16 / 11 / 2011$ & 1 & 0 & 0 & 1 \\
\hline 8.994 & 1.677 & $16 / 11 / 2011$ & 1 & 0 & 0 & 1 \\
\hline 8.997 & 1.879 & $16 / 11 / 2011$ & 0 & 1 & 1 & 1 \\
\hline 6.560 & 1.813 & $4 / 12 / 2011$ & 1 & 0 & 0 & 1 \\
\hline 6.417 & 1.915 & $4 / 12 / 2011$ & 0 & 0 & 0 & 1 \\
\hline 6.889 & 1.854 & $5 / 12 / 2011$ & 0 & 0 & 0 & 0 \\
\hline 7.163 & 1.730 & $5 / 12 / 2011$ & 0 & 0 & 0 & 1 \\
\hline 6.850 & 1.863 & $5 / 12 / 2011$ & 0 & 0 & 0 & 1 \\
\hline 7.088 & 1.808 & $5 / 12 / 2011$ & 0 & 0 & 0 & 1 \\
\hline 8.029 & 2.651 & $6 / 12 / 2011$ & 0 & 0 & 0 & 1 \\
\hline 7.941 & 2.251 & $6 / 12 / 2011$ & 0 & 0 & 0 & 1 \\
\hline 8.191 & 2.623 & $6 / 12 / 2011$ & 0 & 0 & 0 & 1 \\
\hline 7.993 & 2.476 & $6 / 12 / 2011$ & 1 & 0 & 0 & 1 \\
\hline 8.130 & 2.265 & $7 / 12 / 2011$ & 1 & 0 & 1 & 1 \\
\hline 8.219 & 2.004 & $7 / 12 / 2011$ & 0 & 0 & 0 & 1 \\
\hline 8.159 & 2.227 & $7 / 12 / 2011$ & 0 & 0 & 0 & 1 \\
\hline 8.587 & 1.691 & $8 / 12 / 2011$ & 1 & 0 & 1 & 1 \\
\hline 7.833 & 1.694 & $8 / 12 / 2011$ & 0 & 0 & 0 & 1 \\
\hline 7.909 & 1.863 & $8 / 12 / 2011$ & 0 & 0 & 0 & 1 \\
\hline
\end{tabular}




\begin{tabular}{ccc|cccc}
\hline & & & \multicolumn{5}{|c}{ Rhipicephalus } \\
Latitude & Longitude & Date & annulatus & decoloratus & geigyi & microplus \\
\hline 8.332 & 1.882 & $8 / 12 / 2011$ & 1 & 0 & 0 & 1 \\
7.454 & 2.389 & $9 / 12 / 2011$ & 0 & 0 & 0 & 1 \\
7.351 & 1.944 & $9 / 12 / 2011$ & 1 & 0 & 0 & 1 \\
7.396 & 2.069 & $9 / 12 / 2011$ & 0 & 0 & 0 & 1 \\
7.556 & 1.709 & $9 / 12 / 2011$ & 1 & 0 & 0 & 1 \\
7.267 & 2.281 & $10 / 12 / 2011$ & 1 & 0 & 0 & 1 \\
7.158 & 2.491 & $10 / 12 / 2011$ & 0 & 0 & 0 & 1 \\
7.014 & 2.254 & $10 / 12 / 2011$ & 0 & 0 & 0 & 1 \\
7.103 & 2.356 & $10 / 12 / 2011$ & 0 & 0 & 0 & 1 \\
7.057 & 2.123 & $11 / 12 / 2011$ & 0 & 0 & 0 & 1 \\
7.017 & 2.117 & $11 / 12 / 2011$ & 0 & 0 & 0 & 0 \\
6.480 & 2.321 & $11 / 12 / 2011$ & 1 & 0 & 0 & 1 \\
6.672 & 2.368 & $11 / 12 / 2011$ & 0 & 0 & 1 & 1 \\
7.069 & 2.122 & $11 / 12 / 2011$ & 0 & 0 & 0 & 1 \\
6.709 & 2.270 & $11 / 12 / 2011$ & 0 & 0 & 0 & 1 \\
6.577 & 2.342 & $11 / 12 / 2011$ & 0 & 0 & 0 & 1 \\
6.770 & 2.170 & $12 / 12 / 2011$ & 0 & 0 & 0 & 1 \\
6.641 & 2.007 & $12 / 12 / 2011$ & 1 & 0 & 0 & 1 \\
6.730 & 2.502 & $13 / 12 / 2011$ & 0 & 0 & 0 & 1 \\
6.744 & 2.479 & $13 / 12 / 2011$ & 0 & 0 & 1 & 1 \\
6.993 & 2.677 & $13 / 12 / 2011$ & 0 & 0 & 0 & 1 \\
7.297 & 2.636 & $13 / 12 / 2011$ & 0 & 0 & 0 & 1 \\
\hline
\end{tabular}

